\title{
Linguagem e gênero: a construção discursiva de identidades socia is
}

\author{
Linguagem e gênero no \\ trabalho, na mídia e em outros \\ contextos.
}

HEBERLE, Vivia ne M.; OSTERMANN, Ana C.; FIGUEIREDO, Débora.

Florianópolis: Editora da UFSC, 2006. $234 \mathrm{p}$.

Os estud os sobre linguagem e gênero social foram inaugurados na década de $1970 \mathrm{com}$ a publicação de Language and Woman's Place. ${ }^{1}$ Nesse livro, Robin Lakoff argumenta que as mulheres têm um estilo conversacional que privilegia a cooperação, a a filiação e a deferência entre as/os interagentes, 0 que as desempodera em interações com homens que primam pela competitividade e poder em sua forma de falar. Esse livro causou grande comoção na academia estadunidense. Houve os que o consideraram trivial e sem relevância empírica ma is uma manifestação da histeria feminista. No entanto, houve igualmente um grande interesse de acadêmicas/os que valorizaram lou contestaram) os argumentos de Lakoffe lançaram o campo de estudos sobre linguagem e gênero. Desde então, pesquisadoras/es, em sua grande maioria do mundo anglo-saxão, têm elaborado estudos com a intenção de escla recer como a linguagem relaciona-se com o gênero social. Esse campo de estudosjá conta com public açõesem periódicos internacionais, livros e até mesmo programas de graduação e pós-graduação dedicados à pesquisa sobre a construção discursiva do gênero.

No Brasil, a publicação de linguagem e gênero no trabalho, na mídia e em outros contextos pode ser considerada o marco que, felizmente, pode atrair maior a tenção da academia brasileira para os desafios apresentados por esse campo. Viviane Heberle (UFSC), Ana Cristina Ostermann (UNISINOS) e Débora de Carvalho Figueiredo (UNISUL) orga nizara m um livro instigante que reúne artigos de vá ria s/os estudiosa s/os filia da s/os a instituiç ões brasileiras que têm se preocupado com a construção discursiva de gênero social. Essas/es pesquisadoras/es compreendem gênero como "uma categoria socialmente construída" que é, assim "colocada num continuum que interage com outras variá veis socia is, ta is como grau de instrução, etnia, posição religiosa, etc" (p. 9). As organizadoras afimam que a "atualização ou operacionalização de gênero em suas relações com a linguagem não pode serentendida como monolítica e universal" (p. 9) e, seguindo essa perspectiva, nos a presentam textos que exploram a complexidade das relações entre gênero e linguagem em uma plêiade de contextos sociocultura is.

O livro nos presenteia com nove artigos distribuídos em três seções temáticas. As qua tro pesquisas que constroem a primeira seção, intitulada "Gênero, interação e trabalho", estruturam suas a nálises dos mic rodetalhes interacionais sobre preceitos da Análise da Conversa, da Sociolingüística Interacional e/ou da Pragmática.

Ana Cristina Ostermann inic ia o bloco com uma perspicaz análise de detalhes mic roetnográficos de interações em duas organizações formadas por mulheres: uma delegacia de defesa da mulher (DDM) e um centro feminista de intervenção na violência contra a mulher (CIV-Mulher). Ao investigar os aspec tos interaciona is de 26 primeiros encontros de mulheres vítimas de violência com essas instituições, a autora observa que os estilos conversa ciona is das mulheres da DDM e do CIVMulher diferem grandemente. Na DDM, as polic ia is a dotam uma forma de falarempoderada e não afiliativa, o que prejudica a preservação da face (imagem pública positiva) das vítimas. No CIV-Mulher, as feministas, a o contrário, constroem interações mais igualitárias e cooperativas. Assim, Ostermann chama a atenção sobre diferenças "intra gênero" (p. 16). Com seu estudo, a pesquisadora problematiza definições essencialistas sobre as formas de falar de mulheres, sugerindo que genera lizações à la Lakoff não se sustentam na delegacia da mulher investigada. Segundo Ostermann, gênero não pode ser compreendido como molde para pa drões intera c iona is. Os estilos conversa c iona is 
devem ser entend id os como resulta dos de vá rios a tra vessa mentos so c ioc ultura is (como classe, grau de instrução, orientação ideológica, etc.) provenientes das comunidades de práticas nas qua is os indivíduos circulam.

Igualmente analisando variações intragênero, Maria do Carmo de Oliveira, Liliana Cabral Bastose Eliza beth Ba rroso Lima investigam a construção discursiva da identidade empreendedora de uma imigrante portuguesa no Rio de Ja neiro. Ao a nalisa ras histórias de vida de sua entrevista da, as pesquisa doras põem sob escrutínio os tópicos conversaciona is e as qualificações utilizadas pela imigrante para a construção de sua identida de como mulher de negóc ios bem-suc edida. Segundo as a utoras, sua entrevistada mescla padrões de gênero em sua na rrativa e "integra, em sua identida de feminina, competências e a tributos tradicionalmente reconhecidos como típicos de homens empreendedores" (p. 53). Dessa forma, a fala da mulherempreendedora parece sermoldada por valores e comportamentos masculinos que agregam status a sua posição no mercado de trabalho.

No terceiro artigo desse bloco, Neiva Maria Jung mostra como aspectos simbólicos de interações em uma sala de aula de uma comunidade multilíngüe (alemão/português/ brasileiro) paranaense evidenciam construções soc ia is produzida s em outra s prátic as situa das na comunidade. Jung observa, a o efetuar uma a nálise mic roetnográfic a das interações na sala de aula investigada, que uma identidade feminina empoderada é construída na $1^{a}$ a série. A professora dessa turma privilegia o acesso das meninas aos tumos de fala, dando a elas mais oportunidades ao letramento em português ali construído. A pesquisadora indica que o uso do português é visto como índice de sofisticação e urba nidade, sendo preferid o pelas mulheres por Ihes conferir status na comunidade. Os homens, por sua vez, como trabalhadores rurais, ainda mantêm o uso do alemão, índice de uma identidade local de colono. Com isso, Jung verifica que "a orientação a tual das mulheres (+ letrado e - rural), associada a outros fatores socia is, constitui uma nova identida de de gênero nessa comunidade" (p. 87).

0 último a rtigo do bloco investiga estratégias de manutenção do poder de uma ex-chefe em uma reunião empresarial com o novo chefe do departamento. Maria das Graças Dias Pereira a nalisa contextual e interacionalmente questões relaciona das à diretivida de e à ind iretivida de em atos de comando utilizados pela ex-chefe.
Centrando sua a tenção sobre como essa mulher formula pedidos, instruções e recomendações, Pereira observa que ela utiliza estratégias discursivas heterogêneas, mesclando indiretividade (associada a o estilo de fala feminino) e diretivida de (tra dic iona Imente liga da a o estilo masculino) de acordo com seus objetivos interacionais. Quando a ex-chefe dirige-se ao atual chefe do departamento, ela emprega estratégias de domínio e tomada de tumospara deter o piso conversacional, permitindo ao seu atual chefe pouco acesso a o poder construído na reunião. Ao falar com os funcionários, a exchefe produz uma gradação dos atos de comando, mitigando seu poder. Assim, essa mulher constrói suas identidades de forma colaborativa e competitiva, integrando estilos conversaciona is femininos e masculinos para a manutenção de seu status.

A segunda seção, "Gênero e mídia", reúne textos que investigam a construção e a representação do gênero em discursos midiáticos. Os enfoques teóric o-metodológicos centram-se na Análise Crítica do Discurso, no Socioconstrucionismo, na Lingüística de Corpus e nos Estudos de Gêneros Textua is.

"Falta homem até pra homem", por Luiz Paulo da Moita Lopes, é o primeiro texto desse bloco. Ao efetuar uma análise das escolhas multimoda is de uma matéria publicada no jomal popularcarioca O Dia, o autor demonstra como a ordem do discurso da mídia "constrói uma determinada compreensão da masculinidade hegemônica, fazendo circular certas verdades sobre o que é serhomem" (p. 139). O pesquisa dor observa que, para defender seus argumentos, a autora do texto jornalístico utiliza escolhas discursivas que tomam a masculinidade hegemônica como identidade default, considerada como ponto de partida para a descriç ão de outras identida des. Com isso, Moita Lopes indic a que "a ordem do discurso da mídia [...] a tua na construção de uma visão essencia liza da da sidentida des soc ia is (gênero e sexualidade), operando na direção contrá ria dos grandes questionamentos que estão sendo feitos sobre a homogeneidade das experiências humanas" (p. 149).

No segundo artigo desse bloco, Leandro Lemes do Prado e Désirée Motta-Roth investigam as relações interpessoa is e a comodific ação do sujeito em anúncios pessoais (AP) eletrônicos escritos por homens homoerótic os com o objetivo de encontrar parceiros. Autor e autora a nalisam 63 APs em língua inglesa e centram sua a tenção nas esc olhas léxic 0 -g ra ma tic a is efetua das pelos 
anunciantes que revelam o que cada um procura. Em sua análise, Prado e Motta-Roth identificam deferentes perfis do grupo de a nuncia ntes estudado. Os perfis verific a dos nos APs incluem os cautelosos, os misteriosos, os românticos explícitos, os românticos implícitos e os ousados. Autor e autora indicam que os APs a na lisa d os foc a liza $m$ diferentes interesses a fetivosexuais, produzindo relações interpessoa is de compra e venda entre os anunciantes e os possíveis leitores.

Aleksandra Piasecka-Till, no último a rtigo desse bloco, problematiza a questão do sexismo e da linguagem politicamente correta em um estudo lexic al que investiga o Bank of English do Colins Birmingham University International Language Database (COUILD). ${ }^{3}$ A a utora põe sob escrutínio as escolhas lexic a is registra das no corpuspara produziro conceito de politicamente correto. Com uma a purada busca computa cional pelo COBUILD, Pia secka-Till verific ou a oc orrência dos termos sexism, politically correct e political correctness na sociedade de língua inglesa. Com isso, pôde verificar que a mídia cria campos semânticos negativos para envolver o conceito de politicamente correto. A autora argumenta que, com a inclusão de tal conceito em uma esfera semântica negativa, a sociedade de língua inglesa menospreza seu valor e mascara a genda s instituciona is.

Fina Imente, a terceira seção nos a presenta dois artigos que centram suas a nálises na construção social de gênero em contextos diversos: discursos públicos sobre a violência contra a mulhere bares que transmitem jogos de futebol ao vivo. Nos textos reunidos nessa seção são elaboradas a nálises com perspectivas da Aná lise Crítica do Disc urso, dos Estudos J uríd ic os Feministase da Etnografia.

Analisando discursos jurídicos e midiáticos sobre estupro, Débora Figueiredo investiga como estupradores e suas vítimas são construídos/as. Figueiredo observa que "a construção discursiva [do estupro] [...] exerce uma forte influência na forma como a violência de gênero é vista, e como agressores e vítimas são tratados" (p. 202). A pesquisadora percebe que há uma grande preocupação com a sexualidade da mulherque é, nesse contexto, o traço central de sua identidade. Esses discursos trazem mitos produzidospelo senso comum sobre a mulherque é representada pelasfiguras de boa mãe, mulher c asta, mulher promíscua. Os a gressores, a o contrário, têm em sua sexualidade a desculpa para o crime, pois, para o sistema jurídico, o estuprador nem sempre é responsável por seus atos, já que, como representante da masc ulinida de, suas nec essid a des sexua is devem sersupridas. Figueiredo a firma que os julgamentos de estupro são moldados por noções do senso comum sobre homens, mulheres e seus rela cionamentos, tra nsformando em a ção social esses valores. Segundo a autora, esses discursos têm o poder de influenciar como as mulheres vêem sua sexualidade e posição social; são ordens discursivas baseadas em padrões enraizados em nossa sociedade patria rcal.

O c ientista social Édison Gastaldo, no último capítulo da coletânea, investiga as lógicas simbólicas compartilhadas/construídas por homens que assistem a transmissões a o vivo de jogos de futebol em ba res nas cerc a nias de Porto Alegre. O autor elabora uma investigação dos aspectos da sociabilidade desses homens durante o que denomina "relações joc osa sutebolístic as", isto é, interações em que a "sacanagem" dos torc edores de times a d versá rios serve como palco para a construção da masculinidade. Gastaldo argumenta que a sociabilidade de homensnesses bares é um rico locus para a construção de sua masculinidade que é articula da em dois níveis: a) a performance de uma violência pretensa contra torcedores do time adversário e b) a repressão/desvaloriza ção de comportamentos vistos como inapropriados a homens que participam do mundo do futebol.

Linguagem e gênero no trabalho, na mídia e em outros contextos reúne pesquisas que contemplam uma multiplicida de de contextosnos quais gênero é construído pela linguagem. De uma delegacia de defesa da mulhera baresque transmitem jogos de futebol, a coletânea representa uma parcela dascomplexidadesdas relações entre gênero e lingua gem. Fica, então, o desafio: investigar uma gama mais a mpla de contextos sociocultura is para que possamos construir inteligibilida des sobre essas relações. A obra é uma excelente fonte de inspiração para pesquisadoras/es de várias áreas. As organizadoras nos presenteiam com um livro instigante e desafiador. Ao reunir, em um só volume, vários artigos que laçam luz sobre a construção discursiva do gênero, o livro pode ser considera do o marco ina ugural desse campo no Brasil.

\section{Notas}

\footnotetext{
${ }^{1}$ Robin LAKOFF, 1975.

2 Erving GOFFMAN, 1955.

3 Uma coletânea de textos ora is e escritos que documenta o uso do inglês modemo.
} 


\section{Referências bibliográficas}

GOFFMAN, Erving. "On Face-Work: An Analysis of Ritual Elements in Social Interaction." Psychiatry: J ournal for the Study of Interpersonal Processes, v. 18, 1955. p. 213-231.
LAKOFF, Robin. Lamguage and Women's Place. New York: Harper and Row, 1975.

Rodrigo Borba Universidade Federal do Rio de J a neiro 